\title{
Chemoradiotherapy Versus Chemotherapy Alone for Unresected Nonmetastatic Gallbladder Cancer: National Practice Patterns and Outcomes
}

\author{
Vivek Verma, MDª; Swati M. Surkar, PhD ${ }^{\text {b }}$ Eric D. Brooks, MD; Charles B. Simone II, MD; \\ and Chi Lin, MD, PhD
}

\begin{abstract}
Purpose: Current guidelines recommend chemotherapy (CT) with or without radiotherapy for unresected nonmetastatic gallbladder cancer (GC), with little consensus. However, several small-volume, single-institution studies have documented the efficacy of local therapy for this population. This is the largest study to date evaluating outcomes of chemoradiotherapy (CRT) versus CT alone in unresected nonmetastatic GC. Methods: The National Cancer Database was queried for primary GC cases (2004-2013) receiving CT alone or CRT. Patients receiving resection or lack of CT were excluded, as were those with metastatic disease or unknown $\mathrm{M}$ classification. Logistic regression analysis ascertained factors associated with CRT delivery. Kaplan-Meier analysis evaluated overall survival (OS) between both cohorts. Cox proportional hazards modeling determined variables associated with OS. Results: In total, 1,199 patients were analyzed (CRT: $n=327,27 \%$; CT: $n=872$, $73 \%)$. Groups were evenly balanced, with no factor on multivariate logistic regression analysis statistically predicting for receipt of a particular paradigm. Median OS in the CRT and CT groups was 12.9 versus 7.8 months, respectively $(P=.001)$. On multivariate analysis, OS was associated with age and years of treatment ( $P=.001$ each). Notably, receipt of CRT independently predicted for improved OS ( $P=.001)$. Conclusions: CRT, compared with CT alone, was independently associated with improved survival in unresected nonmetastatic GC. Although causation is not implied, these results support the necessity for prospective CRT evaluation.
\end{abstract}

J Natl Compr Canc Netw 2018;16(1):59-65 doi: $10.6004 /$ jnccn.2017.7067

\begin{abstract}
Although rare in the United States, gallbladder cancer (GC) is associated with relatively poor prognosis, especially for unresected cases. NCCN Clinical Practice Guidelines in Oncology (NCCN Guidelines) treatment recommendations for patients with GC include chemotherapy (CT) alone or chemoradiotherapy (CRT), although it is noted that there are limited data to support the CRT option. ${ }^{1}$

Although the addition of local therapy for unresected GC is controversial, it is theoretically appealing for multiple reasons. First, neoplasms of the gallbladder and bile ducts display postoperative patterns of recurrence

From the apepartment of Radiation Oncology, University of Nebraska Medical Center, Fred \& Pamela Buffett Cancer Center, Omaha, Nebraska; ${ }^{b}$ Department of Physical Therapy, Washington University School of Medicine, St. Louis, Missouri; 'Department of Radiation Oncology, University of Texas MD Anderson Cancer Center, Houston, Texas; and ${ }^{d}$ Department of Radiation Oncology, University of Maryland Medical Center, Baltimore, Maryland.
\end{abstract}

that are largely locoregional prior to distant metastasis. It is estimated that just $10 \%$ to $15 \%$ of cases develop distant metastasis prior to locoregional recurrence, indicating that primary postoperative failure is locoregional. ${ }^{2}$ Additionally, locoregional recurrence is the main cause of tumor-related mortality. ${ }^{2}$ Furthermore, in the operative setting, adjuvant radiotherapy (RT) has been associated with survival benefits, potentially implying some level of cellular response and lack of relative radioresistance. ${ }^{3,4}$

Although extrapolating these rationales to unresected cases is problematic, foregoing local therapy
Submitted October 23, 2017; accepted for publication December 4, 2017. The authors have disclosed that they have no financial interests, arrangements, affiliations, or commercial interests with the manufacturers of any products discussed in this article or their competitors.

Correspondence: Chi Lin, MD, PhD, Department of Radiation Oncology, University of Nebraska Medical Center, Fred \& Pamela Buffett Cancer Center, 505 South 45th Street, Omaha, NE 68106. E-mail: clin@unmc.edu 
Verma et al

for unresected disease may risk locoregional tumor progression to the point of symptomatic deterioration, quality-of-life decline, and potentially even a survival detriment. There have been numerous retrospective single-institution reports illustrating numerically high survival rates in patients treated with RT. ${ }^{5-12}$ However, these reports have generally been of limited patient numbers and have consisted of carefully selected patient cohorts and/or encompassed multiple types of biliary malignancies.

This comparative study of a large, contemporary national database of a general US population aimed to evaluate national practice patterns and outcomes of unresected nonmetastatic GC receiving CT alone versus CRT. Although challenging to assess with single- or multi-institutional analyses owing to the relative rarity of this malignancy, the National Cancer Database (NCDB) provides a unique resource with which to address this novel but clinically important issue.

\section{Methods}

The NCDB is a joint project of the Commission on Cancer (CoC) of the American College of Surgeons and the American Cancer Society, which consists of deidentified information regarding tumor characteristics, patient demographics, and patient survival for approximately $70 \%$ of the US population. ${ }^{13-31}$ All pertinent cases are reported regularly from CoC-accredited centers and compiled into a unified data set, which is then validated. The NCDB contains information not captured in the SEER database, including details regarding use of systemic therapy. The data used in the study were derived from a deidentified NCDB file (2004-2013). The American College of Surgeons and the $\mathrm{CoC}$ have not verified and are neither responsible for the analytic or statistical methodology used nor the conclusions drawn from these data by the investigators. Because all patient information in the NCDB is deidentified, this study was exempt from Institutional Review Board evaluation.

Inclusion criteria for this study were patients with newly diagnosed primary GC. Other biliary neoplasms were not included in the assigned data set provided by the NCDB. Patients who underwent resection (defined as wedge/segmental resection, lobectomy, hepatectomy, or surgery not otherwise specified) were excluded, as were those with in situ

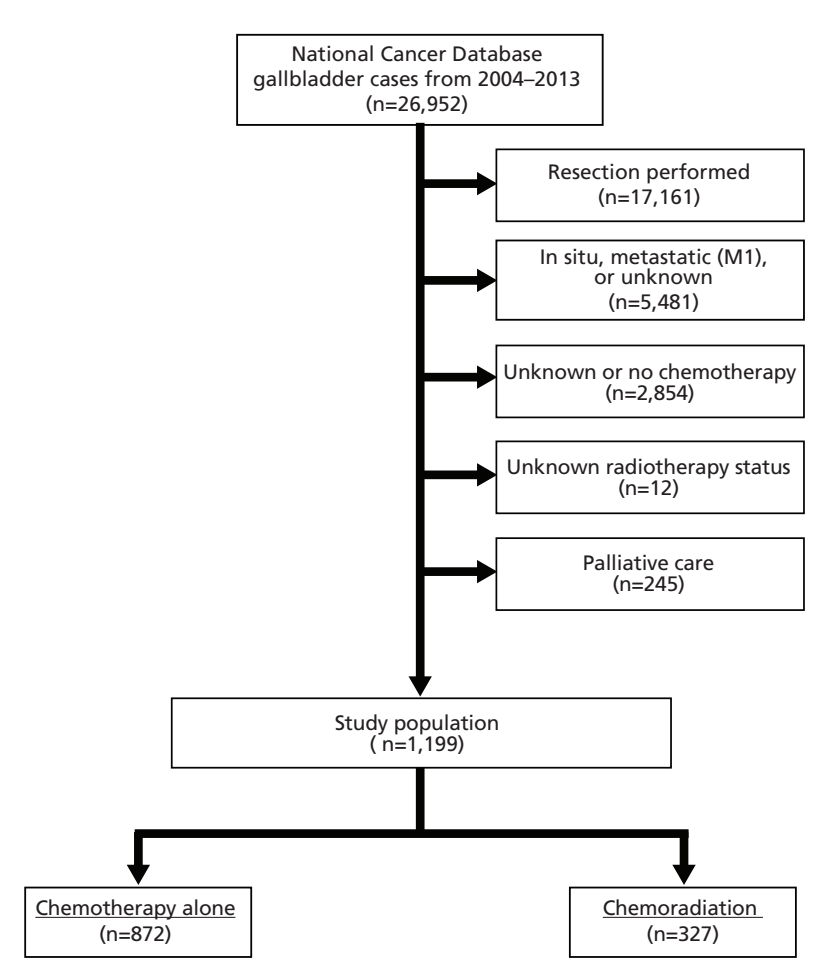

Figure 1. Patient selection diagram for this study, describing the application of several exclusion criteria from the initial database cohort to the population analyzed in this study.

disease, M1 disease, or unknown M classification. All patients were required to receive CT, because this is a category 1 recommendation with level I evidence; patients without CT status were removed. ${ }^{1,32}$ Patients were classified into 2 groups based on receipt of additional RT with CT versus lack of RT; patients with a missing RT status were removed. In accordance with the variables in NCDB files, information collected on each patient broadly included demographic, clinical, and treatment data.

All statistical tests were performed with SPSS software (IBM, Armonk, NY); tests were 2-sided, with a threshold of $P<.05$ for statistical significance. Univariable and multivariable logistic regression were used to determine characteristics associated with receipt of CRT. All initially examined variables were considered for inclusion into models for stepwise selection, except clinical $\mathrm{T}$ and $\mathrm{N}$ classification due to the numerous patients with missing information. Survival analysis (performed using Kaplan-Meier methodology) evaluated overall survival (OS), defined as the interval between date of diagnosis and date of death or censored at last contact. 
CRT vs CT Alone for Gallbladder Cancer

Table 1. Patient Characteristics and Factors Associated With Receiving Chemoradiotherapy

\begin{tabular}{|c|c|c|c|c|c|c|}
\hline \multirow[b]{2}{*}{ Parameter } & \multirow{2}{*}{$\begin{array}{c}\text { CRT } \\
(\mathrm{N}=327)\end{array}$} & \multirow{2}{*}{$\begin{array}{l}\text { CT Alone } \\
(\mathrm{N}=872)\end{array}$} & \multicolumn{2}{|l|}{ Univariable } & \multicolumn{2}{|c|}{ Multivariable (Stepwise) } \\
\hline & & & OR $(95 \% \mathrm{Cl})$ & $P$ Value & OR $(95 \% \mathrm{Cl})$ & $P$ Value \\
\hline Median age (range), y & $67(27-90)$ & $66(26-89)$ & $1.001(0.989-1.012)$ & .916 & & \\
\hline \multicolumn{7}{|l|}{ Sex } \\
\hline Male & $115(35 \%)$ & $301(35 \%)$ & $0.972(0.744-1.269)$ & .833 & & \\
\hline Female & $212(65 \%)$ & $571(65 \%)$ & Ref & & & \\
\hline \multicolumn{7}{|l|}{ Race } \\
\hline White & $258(79 \%)$ & $667(76 \%)$ & $0.827(0.463-1.479)$ & .522 & & \\
\hline Black & $48(15 \%)$ & $147(17 \%)$ & $0.980(0.511-1.878)$ & .951 & & \\
\hline Other & $16(5 \%)$ & $50(6 \%)$ & Ref & & & \\
\hline Unknown & $5(1 \%)$ & $8(1 \%)$ & - & - & & \\
\hline \multicolumn{7}{|l|}{ Charlson-Deyo score ${ }^{a}$} \\
\hline 0 & $251(77 \%)$ & $673(77 \%)$ & $1.087(0.586-2.015)$ & .791 & & \\
\hline 1 & $61(19 \%)$ & $162(19 \%)$ & $1.077(0.552-2.100)$ & .829 & & \\
\hline$\geq 2$ & $15(5 \%)$ & $37(4 \%)$ & Ref & & & \\
\hline \multicolumn{7}{|l|}{ Insurance type } \\
\hline Uninsured & $16(5 \%)$ & $40(5 \%)$ & Ref & & $0.851(0.438-1.655)$ & .635 \\
\hline Private & $103(32 \%)$ & $316(36 \%)$ & $1.245(0.650-2.384)$ & .509 & $1.005(0.534-1.892)$ & .988 \\
\hline Medicaid/Other government & $34(10 \%)$ & $67(8 \%)$ & $0.987(0.537-1.1812)$ & .965 & $0.830(0.614-1.123)$ & .228 \\
\hline Medicare & $161(49 \%)$ & $408(47 \%)$ & $1.211(0.908-1.614)$ & .193 & $1.564(0.967-2.531)$ & .068 \\
\hline Unknown & $13(4 \%)$ & $41(5 \%)$ & $0.778(0.495-1.221)$ & .275 & Ref & \\
\hline \multicolumn{7}{|l|}{ Income (\$USD/y) } \\
\hline$<\$ 30,000$ & $64(20 \%)$ & $171(20 \%)$ & $0.920(0.635-1.334)$ & .661 & & \\
\hline$\$ 30,000-\$ 34,999$ & $62(19 \%)$ & $178(20 \%)$ & $0.989(0.681-1.436)$ & .953 & & \\
\hline$\$ 35,000-\$ 45,999$ & $100(31 \%)$ & $234(27 \%)$ & $0.806(0.578-1.124)$ & .203 & & \\
\hline$\geq \$ 46,000$ & $93(28 \%)$ & $270(31 \%)$ & Ref & & & \\
\hline Unknown & $8(2 \%)$ & $19(2 \%)$ & - & - & & \\
\hline \multicolumn{7}{|l|}{ Location } \\
\hline Metropolitan & $260(80 \%)$ & $749(86 \%)$ & $3.457(1.046-11.422)$ & .042 & $0.299(0.089-1.004)$ & .051 \\
\hline Urban & $41(13 \%)$ & $85(10 \%)$ & $2.488(0.717-8.631)$ & .151 & $0.390(0.111-1.377)$ & .144 \\
\hline Rural & $6(2 \%)$ & $5(1 \%)$ & Ref & & Ref & \\
\hline Unknown & $20(6 \%)$ & $33(4 \%)$ & - & - & & \\
\hline \multicolumn{7}{|l|}{ Adults in zip code without high school diploma } \\
\hline$\geq 21 \%$ & $73(22 \%)$ & $187(21 \%)$ & $0.867(0.586-1.284)$ & .477 & & \\
\hline $13 \%-20.9 \%$ & $81(25 \%)$ & $228(26 \%)$ & $0.953(0.652-1.394)$ & .805 & & \\
\hline $7 \%-12.9 \%$ & $101(31 \%)$ & $249(29 \%)$ & $0.853(0.579-1.204)$ & .333 & & \\
\hline$<7 \%$ & $64(20 \%)$ & $189(22 \%)$ & Ref & & & \\
\hline Unknown & $8(2 \%)$ & $19(2 \%)$ & - & - & & \\
\hline \multicolumn{7}{|l|}{ Facility type } \\
\hline Community & $133(41 \%)$ & $386(44 \%)$ & $1.173(0.905-1.521)$ & .227 & & \\
\hline Academic & $190(58 \%)$ & $470(54 \%)$ & Ref & & & \\
\hline Unknown & $4(1 \%)$ & $16(2 \%)$ & - & - & & \\
\hline \multicolumn{7}{|l|}{ Facility location } \\
\hline Northeast & $70(21 \%)$ & $210(24 \%)$ & $0.871(0.568-1.336)$ & .527 & $1.073(0.686-1.680)$ & .757 \\
\hline South & $113(35 \%)$ & $285(33 \%)$ & $0.732(0.492-1.089)$ & .124 & $1.406(0.932-2.121)$ & .105 \\
\hline Midwest & $95(29 \%)$ & $206(24 \%)$ & $0.630(0.417-0.950)$ & .027 & $1.485(0.968-2.277)$ & .070 \\
\hline West & $45(14 \%)$ & $155(18 \%)$ & Ref & & Ref & \\
\hline Unknown & $4(1 \%)$ & $16(2 \%)$ & - & - & & \\
\hline Median distance to treating facility (range), mi & $11(0-1,300)$ & $9(0-1,437)$ & $0.999(0.998-1.001)$ & .392 & & \\
\hline Clinical T classification & & & & & & \\
\hline 1 & $8(2 \%)$ & $21(2 \%)$ & & & & \\
\hline 2 & $16(5 \%)$ & $23(3 \%)$ & & & & \\
\hline 3 & $126(39 \%)$ & $328(38 \%)$ & & & & \\
\hline 4 & $66(20 \%)$ & $118(14 \%)$ & & & & \\
\hline Unknown & $111(34 \%)$ & $382(44 \%)$ & & & & \\
\hline Clinical N classification & & & & & & \\
\hline 0 & $117(36 \%)$ & $250(29 \%)$ & & & & \\
\hline 1 & $81(25 \%)$ & $183(21 \%)$ & & & & \\
\hline 2 & $16(5 \%)$ & $49(6 \%)$ & & & & \\
\hline Unknown & $113(35 \%)$ & $390(45 \%)$ & & & & \\
\hline Year of diagnosis & & & & & & \\
\hline $2004-2008$ & $172(53 \%)$ & $411(47 \%)$ & Ref & & $1.300(0.994-1.700)$ & .056 \\
\hline $2009-2013$ & $155(47 \%)$ & $461(53 \%)$ & $0.803(0.623-1.036)$ & .092 & Ref & \\
\hline
\end{tabular}

Statistically significant $P$ values are in bold.

Abbreviations: CRT, chemoradiotherapy; CT, chemotherapy; OR, odds ratio.

aThe Charlson-Deyo index is a weighted score of comorbidities as defined by several medical codes. 
Univariate and multivariate Cox proportional hazards modeling was used to evaluate predictors of OS.

\section{Results}

A complete flow diagram of patient selection is provided in Figure 1. In total, 1,199 patients met study analysis criteria; 327 patients (27\%) underwent CRT, whereas $872(73 \%)$ received CT alone (Table 1). Following univariate analysis, multivariable assessment revealed that no factors were independently associated with CRT delivery; this implied that the CRT and CT populations were substantially well balanced. There were, however, trends toward increasing receipt of CRT in Medicare patients $(P=.068)$ and those living in the Midwest $(P=.070)$. Trends were also noted for decreased CRT in the metropolitan population $(P=.051)$ and those treated during more recent periods (2009-2013 vs 2004-2008; $P=.056)$.

Median follow-up was 9 months for all patients (range, 0-123 months). Kaplan-Meier estimates comparing OS in patients who received CT alone versus CRT are illustrated in Figure 2; median OS in the respective cohorts were 7.8 months $(95 \%$ CI, 7.1-8.5) and 12.9 months (95\% CI, 11.0-14.7; $P=.001)$.

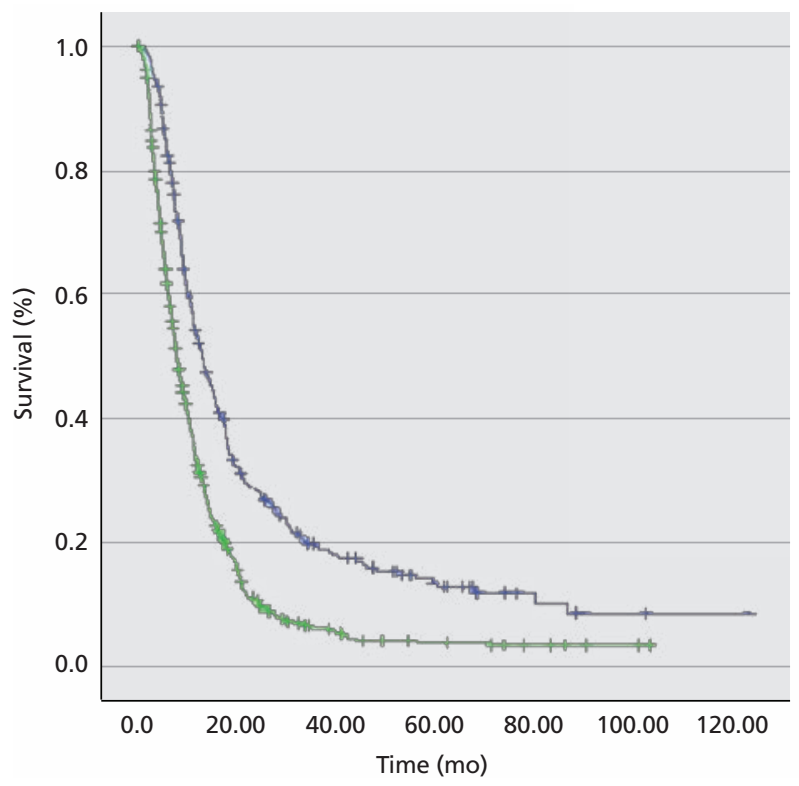

Figure 2. Kaplan-Meier overall survival curve comparing those receiving chemotherapy alone (green) versus chemoradiotherapy (blue), demonstrating statistically superior survival in patients receiving chemoradiotherapy.
In the overall cohort, there were several predictors of OS on univariate analysis (Table 2). After multivariate adjustment for potential confounding factors, factors independently associated with poorer OS included advancing age and diagnosis in prior years $(P=.001$ for both $)$. Of note, receipt of CRT relative to CT alone independently predicted for improved OS (hazard ratio [HR], 0.721; 95\% CI, $0.532-0.979 ; P=.001)$.

\section{Discussion}

Our study of a large, contemporary national database for this relatively rare malignancy-the largest such analysis to date-most notably demonstrates that the addition of RT to CT is independently associated with higher survival in unresected GC. This finding suggests that these hypothesis-generating data should ideally be tested in a prospective study.

These retrospective data may carry selection biases similar to several aforementioned studies, including the potential to perform more aggressive therapy in patients with better risk features or who are better able to tolerate multimodality therapy. In contrast, it is possible that the CRT population was a "higher-risk" cohort and yet still experienced a significantly higher OS. ${ }^{33,34}$ It is intuitive that local therapy may be more often delivered in bulkier cases at higher risk for future/current symptomatology, or potentially owing to doubt that CT alone could sufficiently control the disease. To this extent, a shortcoming of this investigation is the NCDB's lack of information regarding tumor size, which may impact the efficacy of additional RT in this setting ${ }^{35}$; the $\mathrm{T}$ and $\mathrm{N}$ classifications were also largely missing, likely owing to the nonoperative nature of this cohort. Additionally, overall, patients were well balanced (and therefore there was no statistically valid role for propensity matching), without differences in age or comorbidity index. Because all patients received CT, it cannot be said that one group was more "unhealthy" than the other, as both groups were "fit" enough to receive CT. Furthermore, another salient factor was that CRT was less likely given at later periods (2009-2013; $P=.056$ ), but treatment during these periods was independently associated with increased OS on multivariate analysis $(P=.001)$.

The study design further adds credence to the findings regarding CRT versus CT. Although the 
CRT vs CT Alone for Gallbladder Cancer

\begin{tabular}{|c|c|c|c|c|c|c|}
\hline \multirow[b]{2}{*}{ Parameter } & \multicolumn{3}{|c|}{ Univariate } & \multicolumn{3}{|c|}{ Multivariate } \\
\hline & HR & $95 \% \mathrm{Cl}$ & $P$ Value & HR & $95 \% \mathrm{Cl}$ & $P$ Value \\
\hline Treatment group (CRT vs CT alone) & 0.557 & $0.480-0.646$ & .001 & 0.721 & $0.532-0.979$ & .001 \\
\hline Age (continuous) & 1.016 & $1.010-1.022$ & .001 & 1.063 & $1.037-1.090$ & .001 \\
\hline Sex (male vs female) & 0.957 & $0.837-1.093$ & .516 & & & \\
\hline \multicolumn{7}{|l|}{ Race } \\
\hline Black vs white & 0.873 & $0.662-1.151$ & .336 & & & \\
\hline Others vs white & 0.855 & $0.626-1.166$ & .322 & & & \\
\hline \multicolumn{7}{|l|}{ Charlson-Deyo score } \\
\hline 0 vs 2 & 1.014 & $0.743-1.385$ & .931 & & & \\
\hline 1 vs 2 & 1.268 & $0.905-1.776$ & .167 & & & \\
\hline \multicolumn{7}{|l|}{ Insurance } \\
\hline Uninsured vs private & 0.844 & $0.620-1.150$ & .284 & & & \\
\hline Uninsured vs Medicaid/other government & 0.902 & $0.658-1.238$ & .524 & & & \\
\hline Uninsured vs Medicare & 0.791 & $0.686-0.911$ & .001 & & & \\
\hline \multicolumn{7}{|l|}{ Income, \$USD } \\
\hline$<\$ 30,000$ vs $\$ 30,000-\$ 34,999$ & 1.047 & $0.870-1.260$ & .626 & & & \\
\hline$<\$ 30,000$ vs $\$ 35,000-\$ 45,999$ & 0.945 & $0.785-1.138$ & .552 & & & \\
\hline$<\$ 30,000$ vs $\geq \$ 46,000$ & 0.929 & $0.785-1.100$ & .393 & & & \\
\hline \multicolumn{7}{|l|}{ Location } \\
\hline Urban vs metropolitan & 0.679 & $0.352-1.311$ & .249 & 0.522 & $0.270-1.010$ & .054 \\
\hline Rural vs metropolitan & 0.750 & $0.380-1.482$ & .408 & 0.613 & $0.310-1.213$ & .160 \\
\hline \multicolumn{7}{|l|}{ Adults in zip code without high school diploma } \\
\hline $13 \%-20.9 \%$ vs $\geq 21 \%$ & 1.039 & $0.852-1.266$ & .708 & & & \\
\hline $7 \%-12.9 \%$ vs $\geq 21 \%$ & 1.019 & $0.844-1.230$ & .847 & & & \\
\hline$<7 \%$ vs $\geq 21 \%$ & 1.061 & $0.883-1.275$ & .525 & & & \\
\hline Facility type (community vs academic) & 1.148 & $1.008-1.306$ & .037 & & & \\
\hline \multicolumn{7}{|l|}{ Facility location } \\
\hline South vs Northeast & 0.917 & $0.746-1.127$ & .410 & & & \\
\hline Midwest vs Northeast & 0.987 & $0.815-1.196$ & .895 & & & \\
\hline West vs Northeast & 0.944 & $0.771-1.155$ & .573 & & & \\
\hline Distance to treatment facility (continuous) & 1.000 & $0.999-1.000$ & .515 & & & \\
\hline Year of diagnosis (2004-2008 vs 2009-2013) & 1.211 & $1.064-1.379$ & .004 & 1.275 & $1.115-1.458$ & .001 \\
\hline
\end{tabular}

Statistically significant $P$ values are in bold. Only values included in the final multivariate model are shown.

Abbreviations: CRT, chemoradiotherapy; $\mathrm{CT}$, chemotherapy; HR, hazard ratio.

NCDB records RT dose information, we specifically opted not to use this as an inclusion/exclusion criterion. Placing a cutoff may have artificially inflated survival for the CRT group, because the "healthiest" patients would be able to receive and tolerate fulldose RT. By including all patients who underwent RT, we intentionally included those with suboptimal dose and/or tolerance. Despite this, the CRT cohort still displayed a markedly higher OS. Other reasons for not including a dose-based cutoff were that existing studies often use a wide variety of doses, ${ }^{5-12}$ NCCN does not routinely recommend a particular dose for unresected cases, ${ }^{1}$ there was a lack of dose reporting in many cases, and this neoplasm is rare, and therefore limiting patient numbers would not have allowed for adequate sample sizes for comparative analyses. Dose-escalation may be advantageous in these patients to provide "durable local control," which is unsubstantiated in this circumstance but needs further evaluation. Lastly, there was a small group of patients who displayed long-term survival in this study (corresponding to the "tail" in the CRT curve in Figure 2), indicating that local therapy could potentially be curative in a subset of patients.

Although this is the only study of its kind, 2 SEER publications previously attempted to address this question specifically for extrahepatic cholangiocarcinoma. ${ }^{36,37}$ Although both studies found OS improvements with RT versus without, a major advantage of our study is that the SEER database does not contain any information on CT. As such, a proportion of patients in the "no RT" groups in those analyses might not have received any tumor-directed therapy (ie, received supportive care alone). There is reason to believe that many patients in that cohort received supportive care, because not only is it still recommended by the NCCN Guidelines ${ }^{1}$ but also it may have been the standard of care prior to a ran- 
Verma et al

domized trial showing it to be inferior to CT (albeit in a mix of hepatopancreatobiliary neoplasms). ${ }^{32}$ That trial was published in 1996, ${ }^{33}$ whereas both aforementioned SEER studies extracted patients from as early as $1988^{36}$ and $1973 .{ }^{37}$ This bias clearly leads to difficulties in interpretation, and to this extent the information on receipt of CT provided by the NCDB allowed for the selection of a "pure," more modern cohort of patients who all received CT at baseline. Although the NCDB does not provide information on number of cycles, specific agents, or tolerance to CT, it still offers a marked benefit over existing SEER reports.

Consequently, although the NCDB provides a unique platform on which to study this important clinical question, this investigation is not without limitations. First, NCDB studies are inherently retrospective, with selection biases and lack of several end points, such as locoregional control or cancerspecific survival. Second, although we excluded patients undergoing palliative care (per the NCDB variable), definitions of this variable are subject to interpretation and bias. Third, as mentioned previ- ously, the NCDB does not keep track of several other factors, including CT details, performance/functional status, and RT field design/volumes/techniques. Furthermore, information on histology, T/N classification, and tumor size is missing, largely owing to the nonoperative nature of these patients, and was thus not able to be thoroughly analyzed. Additionally, the NCDB does not allow for assessment of subsequent lines of treatment (eg, reirradiation, further systemic and/or targeted therapy), which could influence OS.

\section{Conclusions}

This is the largest study to date evaluating the utility of CRT compared with CT alone for treating unresectable nonmetastatic GC. Administration of CRT was independently associated with improved survival. Nevertheless, causation is not implied, and prospective evidence is necessary to verify the conclusions presented herein. The accruing NRG-GI001 randomized trial is evaluating a similar question for intrahepatic cholangiocarcinoma (ClinicalTrials. gov identifier: NCT02200042).

\section{References}

1. Benson AB III, D'Angelica MI, Abbot D, et al. NCCN Clinical Practice Guidelines in Oncology: Hepatobiliary Cancers. Version 3.2017. Accessed September 19, 2017. To view the most recent version of these guidelines, visit NCCN.org.

2. Macdonald $\mathrm{OK}$, Crane $\mathrm{CH}$. Palliative and postoperative radiotherapy in biliary tract cancer. Surg Oncol Clin N Am 2002;11:941-954.

3. Hoehn RS, Wima K, Ertel AE, et al. Adjuvant therapy for gallbladder cancer: an analysis of the National Cancer Data Base. J Gastrointest Surg 2015;19:1794-1801.

4. Mantripragada KC, Hamid F, Shafqat $H$, Olszewski AJ. Adjuvant therapy for resected gallbladder cancer: analysis of the National Cancer Data Base. J Natl Cancer Inst 2016;109:djw202.

5. Grove MK, Hermann RE, Vogt DP, Broughan TA. Role of radiation after operative palliation in cancer of the proximal bile ducts. Am J Surg 1991;161:454-458.

6. Tollenaar RA, van de Velde CJ, Taat CW, et al. External radiotherapy and extrahepatic bile duct cancer. Eur J Surg 1991;157:587-589.

7. Buskirk SJ, Gunderson LL, Schild SE, et al. Analysis of failure after curative irradiation of extrahepatic bile duct carcinoma. Ann Surg 1992;215:125-131.

8. Lu JJ, Bains YS, Abdel-Wahab M, et al. High-dose-rate remote afterloading intracavitary brachytherapy for the treatment of extrahepatic biliary duct carcinoma. Cancer J 2002;8:74-78.

9. Crane $\mathrm{CH}$, Macdonald $\mathrm{KO}$, Vauthey JN, et al. Limitations of conventional doses of chemoradiation for unresectable biliary cancer. Int J Radiat Oncol Biol Phys 2002;53:969-974.

10. Deodato F, Clemente G, Mattiucci GC, et al. Chemoradiation and brachytherapy in biliary tract carcinoma: long-term results. Int J Radiat Oncol Biol Phys 2006;64:483-488.

11. Ghafoori AP, Nelson JW, Willett CG, et al. Radiotherapy in the treatment of patients with unresectable extrahepatic cholangiocarcinoma. Int J Radiat Oncol Biol Phys 2011;81:654-659.

12. Habermehl D, Lindel $K$, Rieken $S$, et al. Chemoradiation in patients with unresectable extrahepatic and hilar cholangiocarcinoma or at high risk

for disease recurrence after resection: analysis of treatment efficacy and failure in patients receiving postoperative or primary chemoradiation. Strahlenther Onkol 2012;188:795-801.

13. Bilimoria KY, Stewart AK, Winchester DP, Ko CY. The National Cancer Data Base: a powerful initiative to improve cancer care in the United States. Ann Surg Oncol 2008;15:683-690.

14. Stahl JM, Corso CD, Verma V, et al. Trends in stereotactic body radiation therapy for stage I small cell lung cancer. Lung Cancer 2017;103:11-16.

15. Haque W, Verma V, Butler EB, Teh BS. Patterns of care and outcomes of multi-agent versus single-agent chemotherapy as part of multimodal management of low grade glioma. J Neurooncol 2017;133:369-375.

16. Haque W, Verma V, Butler EB, Teh BS. National practice patterns and outcomes for T4b urothelial cancer of the bladder [published online ahead of print September 6, 2017]. Clin Genitourin Cancer, doi:10.1016/j. clgc.2017.08.013.

17. Moreno AC, Verma V, Hofstetter WL, Lin SH. Patterns of care and treatment outcomes of elderly patients with stage I esophageal cancer: analysis of the National Cancer Data Base. J Thorac Oncol 2017;12:11521160 .

18. McMillan MT, Ojerholm E, Verma V, et al. Radiation treatment time and overall survival in locally advanced non-small cell lung cancer. Int J Radiat Oncol Biol Phys 2017;98:1142-1152.

19. Verma V, Ryckman JM, Simone CB II, Lin C. Patterns of care and outcomes with the addition of chemotherapy to radiation therapy for stage I nasopharyngeal cancer [published online ahead of print July 19, 2017]. Acta Oncol, doi:10.1080/0284186X.2017.1351039.

20. Verma V, Ahern CA, Berlind CG, et al. National Cancer Data Base report on pneumonectomy versus lung-sparing surgery for malignant pleural mesothelioma. J Thorac Oncol 2017;12:1704-1714.

21. Haque W, Verma V, Butler EB, Teh BS. Definitive chemoradiation at high volume facilities is associated with improved survival in glioblastoma. J Neurooncol 2017;135:173-181.

22. Haque W, Verma V, Butler EB, Teh BS. Radical cystectomy versus chemoradiation for muscle-invasive bladder cancer: impact of treatment facility and sociodemographics. Anticancer Res 2017;37:5603-5608. 
CRT vs CT Alone for Gallbladder Cancer

23. Bott MJ, Patel AP, Verma V, et al. Patterns of care in hilar node-positive (N1) non-small cell lung cancer: a missed treatment opportunity? J Thorac Cardiovasc Surg 2016;151:1549-1558.

24. Haque W, Verma V, Butler EB, Teh BS. Radiation dose in neoadjuvant chemoradiation therapy for esophageal cancer: patterns of care and outcomes from the National Cancer Data Base [published online ahead of print September 22, 2017]. J Gastrointest Oncol 2017, doi: 10.21037/ jgo.2017.09.12

25. Verma V, Simone CB, Lin C. Human papillomavirus and nasopharyngeal cancer. Head Neck 2017, doi: 10.1002/hed.24978.

26. Haque W, Verma V, Butler EB, Teh BS. Addition of chemotherapy to hypofractionated radiotherapy for glioblastoma: practice patterns, outcomes, and predictors of survival [published online ahead of print October 31, 2017]. J Neurooncol 2017, doi: 10.1007/s11060-017-2654-y.

27. Verma V, Allen PK, Simone CB II, et al. Association of treatment at highvolume facilities with survival in patients receiving chemoradiotherapy for nasopharyngeal cancer [published online ahead of print November 2, 2017]. JAMA Otolaryngol Head Neck Surg 2017, doi:10.1001/ jamaoto.2017.1874.

28. Verma V, Allen PK, Simone CB II, et al. Addition of definitive radiotherapy to chemotherapy in patients with newly diagnosed metastatic nasopharyngeal cancer. J Natl Compr Canc Netw 2017;15:1383-1391.

29. Haque W, Verma V, Butler EB, Teh BS. Chemotherapy versus chemoradiation for node-positive bladder cancer: practice patterns and outcomes from the National Cancer Data Base. Bladder Cancer 2017;3:283-291.

30. Haque W, Verma V, Bernicker E, et al. Management of pathologic nodepositive disease following initial surgery for clinical T1-2 NO esophageal cancer: patterns of care and outcomes from the National Cancer Data Base [published online ahead of print November 30, 2017]. Acta Oncol 2017, doi: 10.1080/0284186X.2017.1409435.

31. Haque $\mathrm{W}$, Lewis GD, Verma $\mathrm{V}$, et al. The role of adjuvant chemotherapy in locally advanced bladder cancer [published online ahead of print December 11, 2017]. Acta Oncol 2017, doi: 10.1080/0284186X.2017.1415461.

32. Glimelius B, Hoffman K, Sjoden PO, et al. Chemotherapy improves survival and quality of life in advanced pancreatic and biliary cancer. Ann Oncol 1996;7:593-600.

33. Haque $\mathrm{W}$, Verma V, Fakhreddine $\mathrm{M}$, et al. Addition of chemotherapy to definitive radiotherapy for IB1 and IIA1 cervical cancer: analysis of the National Cancer Data Base. Gynecol Oncol 2017;144:28-33.

34. Verma V, McMillan MT, Grover S, et al. Stereotactic body radiation therapy and the influence of chemotherapy on overall survival for large ( 25 centimeter) non-small cell lung cancer. Int J Radiat Oncol Biol Phys 2017;97:146-154.

35. Brunner TB, Schwab D, Meyer T, Sauer R. Chemoradiation may prolong survival of patients with non-bulky unresectable extrahepatic biliary carcinoma. A retrospective analysis. Strahlenther Onkol 2004;180:751757.

36. Shinohara ET, Mitra N, Guo M, Metz JM. Radiotherapy is associated with improved survival in adjuvant and palliative treatment of extrahepatic cholangiocarcinomas. Int J Radiat Oncol Biol Phys 2009;74:1191-1198.

37. Fuller CD, Wang SJ, Choi M, et al. Multimodality therapy for locoregional extrahepatic cholangiocarcinoma: a population-based analysis. Cancer 2009;115:5175-5183.

\section{Register now at NCCN.org/academy}

\section{NCCN Academy for Excellence \& Leadership in Oncology ${ }^{\mathrm{TM}}$ School of Pharmaceutical \& Biotech Business}

A one-day session held in conjunction with the NCCN 23 ${ }^{\text {rd }}$ Annual Conference

Wednesday, March 21, 2018 • Rosen Shingle Creek • Orlando, Florida

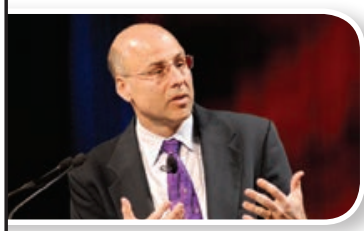

Moderator: Clifford Goodman, PhD Senior Vice President The Lewin Group

\section{Save $\$ 100$ ! Enroll by Monday, February 12, 2018}

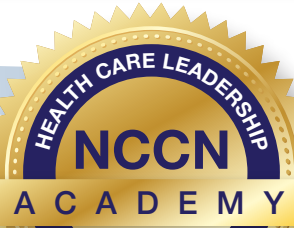

A C A D E M Y

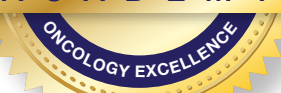

Celebrating

10 Years
Module I: Discovery and Innovation Redefining Cancer Care, Quality, and Value

Module II: Meet the NCCN Guidelines ${ }^{\circledR}$ Panel Experts

Module III: Supporting the Patient Journey: Advances and Best Practices in Supportive Care, Survivorship, and Patient Advocacy
By attending, professionals will be able to:

- Hear directly from NCCN Guidelines ${ }^{\circledR}$ Panel Members

- Improve working knowledge of key business, policy, coverage, reimbursement, informational, and operational issues in oncology

- Gather valuable insights into developing effective strategies for navigating the various constituencies in cancer care

Visit NCCN.org/academy to enroll and to access the complete program curriculum. 